\title{
Dynamics of Quinolone Resistance in Fecal Escherichia coli of Finishing Pigs after Ciprofloxacin Administration
}

\author{
Kang HUANG ${ }^{1}$, Chang-Wen XU1), Bo ZENG ${ }^{1}$, Qing-Qing XIA ${ }^{1}$, , An-Yun ZHANG ${ }^{1}$, Chang-Wei LEI ${ }^{1)}$, \\ Zhong-Bin GUAN ${ }^{1)}$, Han $\mathrm{CHENG}^{1)}$ and Hong-Ning WANG ${ }^{1) *}$ \\ ${ }^{1)}$ School of Life Science, Sichuan University, Animal Disease Prevention and Food Safety Key Laboratory of Sichuan Province, Key \\ Laboratory of Bio-resources and Eco-environment, Ministry of Education, "985 Project" Science Innovative Platform for Resource and \\ Environment Protection of Southwestern China, Chengdu, Sichuan 610064, P. R. China
}

(Received 14 January 2014/Accepted 12 May 2014/Published online in J-STAGE 12 June 2014)

\begin{abstract}
Escherichia coli resistance to quinolones has now become a serious issue in large-scale pig farms of China. It is necessary to study the dynamics of quinolone resistance in fecal Escherichia coli of pigs after antimicrobial administration. Here, we present the hypothesis that the emergence of resistance in pigs requires drug accumulation for 7 days or more. To test this hypothesis, 26 pigs ( 90 days old, about $30 \mathrm{~kg}$ ) not fed any antimicrobial after weaning were selected and divided into 2 equal groups: the experimental (EP) group and control (CP) group. Pigs in the EP group were orally treated daily with $5 \mathrm{mg}$ ciprofloxacin $/ \mathrm{kg}$ of body weight for 30 days, and pigs in the $\mathrm{CP}$ group were fed a normal diet. Fresh feces were collected at 16 time points from day 0 to day 61 . At each time point, ten $E$. coli clones were tested for susceptibility to quinolones and mutations of gyrA and parC. The results showed that the minimal inhibitory concentration (MIC) for ciprofloxacin increased 16-fold compared with the initial MIC $(0.5 \mu \mathrm{g} / \mathrm{m} l)$ after ciprofloxacin administration for 3 days and decreased 256-fold compared with the initial MIC $(0.5 \mu \mathrm{g} / \mathrm{m} l)$ after ciprofloxacin withdrawal for 26 days. GyrA (S83L, D87N/ D87Y) and parC (S80I) substitutions were observed in all quinolone-resistant $E$. coli (QREC) clones with an MIC $\geq 8 \mu \mathrm{g} / \mathrm{m} l$. This study provides scientific theoretical guidance for the rational use of antimicrobials and the control of bacterial resistance. KEY WORDS: ciprofloxacin, dynamics, Escherichia coli, quinolone resistance, swine
\end{abstract}

doi: 10.1292/jvms.14-0025; J. Vet. Med. Sci. 76(9): 1213-1218, 2014

Escherichia coli is a common porcine enteric bacterium. There exist $E$. coli strains that cause neonatal and postweaning diarrhea and edema disease $[10,16]$. These 2 diseases are responsible for considerable economic losses worldwide due to mortality, morbidity, decreased growth rate and the cost of medication $[3,10]$. To reduce the economic losses, different kinds of antimicrobials have been used for many years in pig farms all over the world [33]. However, the use of antimicrobials leads to selection of resistant bacteria, such as antimicrobial-resistant E. coli [32]. In China, quinolones have been widely used in medical science and veterinary clinic for many years. For this reason, E. coli resistance to quinolones has now become a serious issue in China $[6,18,33]$. Recent research shows that quinolone-resistant E. coli (QREC) from farm animals in China is more prevalent than in other countries [17].

As a natural reservoir of bacterial resistance, the fecal microbiota of animals plays an important role in the spread

\footnotetext{
*Correspondence to: Wang, H.-N., School of Life Science, Sichuan University, Animal Disease Prevention and Food Safety Key Laboratory of Sichuan Province, Key Laboratory of Bio-resources and Eco-environment, Ministry of Education, "985 Project" Science Innovative Platform for Resource and Environment Protection of Southwestern China, Chengdu, Sichuan 610064, P. R. China. e-mail: whongning@163.com.

(C)2014 The Japanese Society of Veterinary Science

This is an open-access article distributed under the terms of the Creative Commons Attribution Non-Commercial No Derivatives (by-nc-nd) License $<$ http://creativecommons.org/licenses/by-nc-nd/3.0/>.
}

of bacterial resistance, because it contains great numbers and various kinds of bacteria [2]. There are mainly 4 reasons for the appearance of resistance in the fecal microbiota: 1. de novo selection of resistance mutants from the initial microbiota, 2. enrichment of QREC in the initial gut microbiota, 3. horizontal transfer of plasmid-mediated quinolone resistance genes and 4. exogenously acquired resistant bacteria $[8,11]$.

$E$. coli is a prevalent intestinal bacterium in animals and humans, and the level of antimicrobial resistance in intestinal $E$. coli can be used as a valid indicator for study about selection pressure in bacteria exposed to antimicrobials [5]. Selective pressure exerted by the use of antimicrobials appears to induce the E. coli resistance [32]. How QREC is induced has been well reported by in vitro studies for many years [9, 14]. But, conclusions from these studies do not well reflect the reality in vivo, as the environment in vivo is complex. Recently, the dynamics and diversity of $E$. coli populations in swine intestines under large-scale farming conditions have been reported [20]. Also, how antimicrobial use influences gut bacterial resistance in pigs has been explained by using metagenomic sequencing and quantitative PCR-based approaches [19, 34]. However, the ciprofloxacin resistance of $E$. coli from feces of pigs on large-scale pig farms and its dynamic changing pattern have not been clearly revealed. The time required for development of resistance is also unclear. In the pig industry in China, prophylactic antimicrobial therapy is usually used for 7 days to prevent disease. Based on this reality, the aim of our study was to investigate the effect of in-feed ciprofloxacin on the dynamics of resistance to quinolones in fecal E. coli of pigs 
Table 1. Primers used in this study

\begin{tabular}{|c|c|c|c|c|c|}
\hline Target gene & Primers & Sequence $\left(5^{\prime}-3^{\prime}\right)$ & Size (bp) & $\begin{array}{c}\text { Annealing } \\
\text { temperature } \\
\left({ }^{\circ} \mathrm{C}\right)\end{array}$ & Accession no. \\
\hline \multirow[t]{2}{*}{$q n r B$} & $q n r B-\mathrm{F}$ & CGACCTGAGCGGCACTGAAT & \multirow{2}{*}{515} & \multirow{2}{*}{57.5} & \multirow{2}{*}{ DQ351241 } \\
\hline & $q n r B-\mathrm{R}$ & TGAGCAACGATGCCTGGTAG & & & \\
\hline \multirow[t]{2}{*}{$q n r S$} & $q n r S-\mathrm{F}$ & CATACATATCGGCACCACAAC & \multirow{2}{*}{637} & \multirow{2}{*}{56} & \multirow{2}{*}{ EF683584 } \\
\hline & $q n r S-\mathrm{R}$ & CAGGATAAACAACAATACCCAGT & & & \\
\hline \multirow[t]{2}{*}{ aac (6') Ib-cr } & aac $-\mathrm{F}$ & TTGCGATGCTCTATGAGTGGCTA & \multirow{2}{*}{482} & \multirow{2}{*}{55} & \multirow{2}{*}{ EF465463 } \\
\hline & aac $-\mathrm{R}$ & CTCGAATGCCTGGCGTGTTT & & & \\
\hline \multirow[t]{2}{*}{$o q x A B$} & $o q x A B-\mathrm{F}$ & GATCAGTCAGTGGGATAGTTT & \multirow{2}{*}{627} & \multirow{2}{*}{55} & \multirow{2}{*}{ HQ674771 } \\
\hline & $o q x A B-\mathrm{R}$ & TACTCGGCGTTAACTGATTA & & & \\
\hline
\end{tabular}

on a large-scale pig farm and to test the hypothesis that the emergence of resistance in pigs requires drug accumulation for 7 days or more.

\section{MATERIALS AND METHODS}

Study design: The study was performed from July 2011 to September 2011 at a commercial pig farm located in Jitian Village, Shuangliu County, Chengdu, Sichuan Province, China. The pig farm was far from the city and has normal breeding management. There had been no mass outbreaks of disease and less antimicrobial use at the farm in the past year. A total of 26 finishing pigs were selected and divided into the following 2 groups: the experimental (EP) group and the control (CP) group. Each group of pigs was placed in different pens, and the 2 groups were managed by a single stockman.

The detailed characteristics of the pigs were as follows: 1. Landrace, Duroc and Yorkshire crossbred pigs (mixed males and females), 2. same ages (90 days old) with an average weight of $30 \mathrm{~kg}, 3$. normal body temperature and normal fecal consistency and 4. no antimicrobial treatment in the past month.

Antimicrobial administration and sampling: Pigs were fed a control diet for 2 weeks before sampling. Pigs in the EP group were orally fed ciprofloxacin (150 mg per pig) once per day at noon for 30 days. We performed the feeding procedure in 2 steps: 1) Half the fodder (by weight) was taken out, and an antimicrobial solution was sprayed onto it by mixing; the mixture was then added into the corresponding feeder. 2) After the pigs ate all the mixture, the other half of the fodder without the antimicrobial was added in so that all the antimicrobials were eaten by pigs. No antimicrobials were used for the pigs in the $\mathrm{CP}$ group. The feeder would clean the floor of each pen after feeding the pigs. Fresh feces $(>5 \mathrm{~g})$ were picked from 5 different locations in each pen and mixed immediately. Fecal samples were collected at noon on each sampling day within $1 \mathrm{hr}$ post feeding. They were collected on days $0,1,2,4,6,11,16,21,26,31,36,41,46$, 51,56 and 61 . The fecal samples were placed into an ice box and transported to laboratory within $2 \mathrm{hr}$.

Counting of drug-resistant E. coli and total E. coli in fecal samples: One gram of each fecal sample was suspended in $10 \mathrm{~m} l$ PBS buffer $(0.05 \mathrm{M})$, and the supernatant was col- lected after the sample was mixed fully. The supernatant was serially diluted 10 -fold by using PBS buffer $(0.05 \mathrm{M})$, and then $0.1 \mathrm{ml}$ of each dilution, including the original dilution, was spread onto 2 types of culture medium: EMB agar (Becton, Dickinson and Co., Sparks, MD, U.S.A.) containing no ciprofloxacin and ciprofloxacin-plus EMB (CIP+EMB) agar containing $4 \mu \mathrm{g} / \mathrm{m} l$ ciprofloxacin. After $24 \mathrm{hr}$ of incubation at $37^{\circ} \mathrm{C}$, the numbers of QREC and total E. coli in feces were calculated according to the countable isolates on agar plates, and $10 \mathrm{E}$. coli clones were randomly picked from EMB agar for further analysis.

Bacterial isolates and susceptibility testing: All the E. coli clones were identified by classical biochemical methods and confirmed with an API 20E system (bioMérieux, France). The susceptibility to quinolones of the $E$. coli clones was tested by determining the minimal inhibitory concentration (MIC, 0.0078125-256 $\mu \mathrm{g} / \mathrm{m} l$ ). The agar dilution method described by the Clinical and Laboratory Standards Institute (CLSI) was used to test the MIC of the antimicrobials, ciprofloxacin, nalidixic acid, norfloxacin and levofloxacin [4]. E. coli clones were considered resistant or susceptible according to a standard introduced by the CLSI [4]. The reference $E$. coli strain ATCC 25922 was used as an internal control in this study.

Statistical analysis for the MICs of E. coli clones in the EP and CP groups: After the MICs of E. coli clones from both the EP and CP groups were determined, we used the $t$ test in SPSS (Statistical Product and Service Solutions) 13.0 software to analyze the salient differences in the MICs of $E$. coli clones between different points of time in the EP group and between the EP and CP groups. The E. coli clones were from the fecal samples collected on day $0,1,4,6,11,31,41$, 51 and 61.

DNA sequence analysis and genotypic comparison of $E$. coli clones: By using the boiling method, DNA of $E$. coli clones was extracted and reserved at $-80^{\circ} \mathrm{C}$ until use. The quinolone resistance-determining region (QRDR) genes (gyrA, parC) were found to have point mutations with primers described previously $[13,23]$. Four plasmidmediated quinolone resistance (PMQR) genes ( $q n r B, q n r S$, $a a c$ (6')-Ib-cr, and oqxAB) were detected by PCR with the primers shown in Table 1. All the reactions were carried out in a final volume of $25 \mu l$ containing $2.5 \mu l$ of $10 \times \mathrm{Ex}$ Taq Buffer, $2 \mu l$ of $\mathrm{MgCl}_{2}(25 \mathrm{mM}), 2 \mu l$ of $\mathrm{dNTP}(2.5 \mathrm{mM})$, 


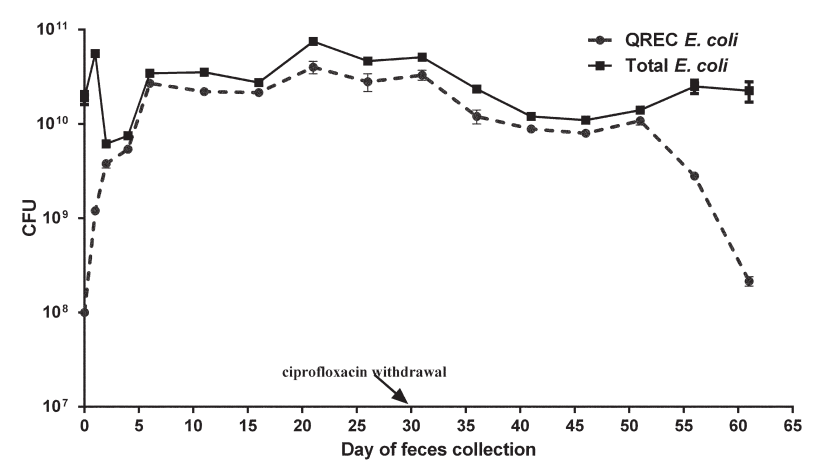

Fig. 1. The number of QREC and total E. coli strains in fecal samples collected from experimentally treated pigs at 16 time points.

$0.25 \mu l$ of TaKaRa Ex Taq $(5 \mathrm{U} / \mu l), 0.5 \mu l$ of each primer $(25 \mathrm{M})$ and $1 \mu l$ of DNA samples. Homologous analysis of $E$. coli clones was performed through enterobacterial repetitive intergenic consensus (ERIC) PCR amplification as described previously [7]. PCR amplicons were analyzed on 1.5\% (wt/ vol) agarose gels. The Quantity One 4.6.2 Software was used to analyze genetic relationships among different isolates. Similarity between fingerprints was calculated with the Dice coefficient. Cluster analysis was performed using the unweighted pair-group method with average linkages.

Monitoring of bacterial growth: The growth rates of $E$. coli clones from 3 stages (before ciprofloxacin administration, after ciprofloxacin administration and after ciprofloxacin withdrawal) were determined by the method described previously [12]. For each of the 3 stages, 5 E. coli clones were selected to measure the optical density at $600 \mathrm{~nm}$ $\left(\mathrm{OD}_{600}\right)$ in Luria-Bertani (LB) medium. All the clones were initially cultured in $\mathrm{LB}$ medium at $37^{\circ} \mathrm{C}$ for $16 \mathrm{hr}$, and then, the bacterial suspension was diluted to a determined density $\left(10^{5} \mathrm{CFU}\right)$; finally, $0.1 \mathrm{~m} l$ of the diluted culture was transferred into $3 \mathrm{~m} l \mathrm{LB}$ medium for measuring the $\mathrm{OD}_{600}$. The optical density was detected every 20 or $30 \mathrm{~min}$.

\section{RESULTS}

The number of QREC and total E. coli isolates: Fecal samples contained a certain amount $\left(10^{8} \mathrm{CFU}\right.$ per gram of feces) of QREC isolates before ciprofloxacin administration, and the amount of total $E$. coli isolates was $10^{10} \mathrm{CFU}$ per gram of feces. After ciprofloxacin administration, the number of QREC isolates increased from $10^{8} \mathrm{CFU}$ to $10^{9} \mathrm{CFU}$, and on day 6 , the amount was stable $\left(10^{10} \mathrm{CFU}\right)$. The number of total E. coli isolates decreased obviously from $10^{10} \mathrm{CFU}$ to $10^{9} \mathrm{CFU}$ after ciprofloxacin administration, but returned to a stable level on day $6\left(10^{10} \mathrm{CFU}\right)$. After withdrawal, the numbers of QREC isolates and total $E$. coli isolates gradually decreased, and on day 56, they finally decreased to the initial level seen before ciprofloxacin administration (Fig. 1).

Antimicrobial resistance testing and statistical analysis: A total of $240 \mathrm{E}$. coli clones (160 clones from the EP group and 80 clones from the $\mathrm{CP}$ group) were examined with the

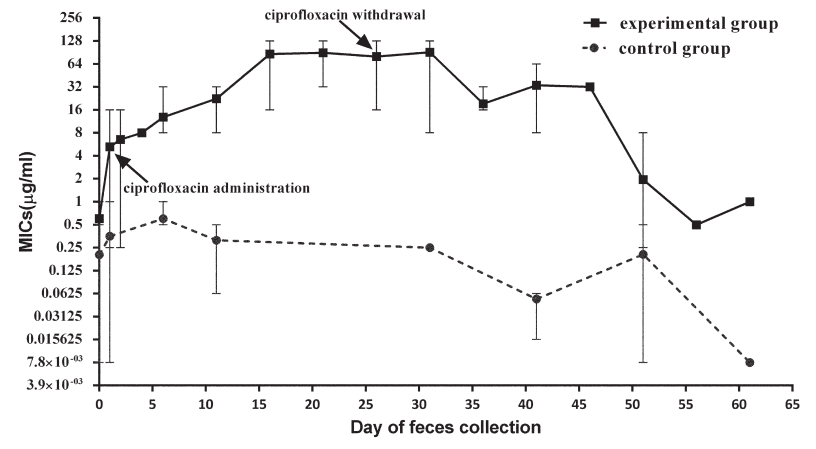

Fig. 2. The average MIC of $E$. coli clones $(\mathrm{n}=10)$ from fecal samples at 16 time points in the experimental group of pigs and at 8 time points in the control group of pigs. Bars indicate the standard deviation between MICs.

API 20E system. The results concerning the dynamics of the MICs for the $240 \mathrm{E}$. coli clones are shown in Fig. 2. In the EP group, after 3 days of ciprofloxacin administration, the MIC for ciprofloxacin increased from 0.5 to $8 \mu \mathrm{g} / \mathrm{m} l$ (16fold); after 26 days of ciprofloxacin withdrawal, the MIC decreased from 128 to $0.5 \mu \mathrm{g} / \mathrm{m} l$ in the EP group. The MICs for the $80 \mathrm{E}$. coli clones in the $\mathrm{CP}$ group maintained a stable value $(<1 \mu \mathrm{g} / \mathrm{m} l)$. According to the statistical analysis, the MICs for the E. coli clones showed no significant difference between the EP and CP groups, in which the fecal samples were collected on days 0,51 and $61(P>0.05)$, but there were significant differences between the 2 groups in which the fecal samples were collected on days $1,6,11,31$ and $41(P<0.05)$. In the EP group, after 3 days of ciprofloxacin administration, the MICs for the $E$. coli clones showed significant differences compared with the $E$. coli clones from before ciprofloxacin administration (day 0).

Detection of PMQR genes and mutations in QRDR genes: The PMQR genes (qnrB, qnrS, aac (6')-Ib-cr and oqxAB) were not detected in both the EP and CP groups. Only the position 83 mutation of $g y r A$ was detected in some of the $E$. coli clones in the $\mathrm{CP}$ group during the whole study. In the EP group, only the position 83 mutation of gyrA was detected before ciprofloxacin administration. After ciprofloxacin administration, the position 83 and 87 mutations of gyrA and the position 80 mutation of parC were detected in $E$. coli clones with an MIC $\geq 8 \mu \mathrm{g} / \mathrm{m} l$. After 26 days of ciprofloxacin withdrawal, only the position 83 mutation of gyrA was detected (Table 2).

Homology of E. coli clones: Cluster analysis of ERICPCR profiles of the $E$. coli clones from the 3 stages (before ciprofloxacin administration, after ciprofloxacin administration and after ciprofloxacin withdrawal) revealed a low level of similarity among the strains (61-79\%).

Growth rates of E. coli clones: The $E$. coli clones we used to measure growth rates were quinolones susceptible $E$. coli (QSEC) from feces before ciprofloxacin administration (day 0 ) and after ciprofloxacin withdrawal (day 61); and the $E$. coli clones after ciprofloxacin administration (day 26) were QREC clones. The QREC clones showed lower growth rates 
Table 2. Characteristics of E. coli isolates isolated from the fecal samples of pigs fed ciprofloxacin from days 1 to 30

\begin{tabular}{|c|c|c|c|c|c|c|c|c|}
\hline \multirow{2}{*}{ CIP use } & \multirow{2}{*}{$\begin{array}{l}\text { Day of feces } \\
\text { collection }\end{array}$} & \multicolumn{4}{|c|}{ Max MIC $(\mu \mathrm{g} / \mathrm{m} l)$} & \multicolumn{2}{|r|}{ gyrA } & \multirow{2}{*}{$\frac{\operatorname{par} C}{\text { mut } 80(\mathrm{n})}$} \\
\hline & & CIP & NAL & NOR & LVX & mut $83(\mathrm{n})$ & mut 87 (n) & \\
\hline $\begin{array}{l}\text { Before ciprofloxacin } \\
\text { administration }\end{array}$ & 0 & 1 & 64 & 1 & 1 & S83L (4) & $\cdots$ & $\cdots$ \\
\hline \multirow{8}{*}{$\begin{array}{c}\text { After CIP } \\
\text { administration }\end{array}$} & 1 & 16 & 512 & 16 & 16 & S83L (6) & $\mathrm{D} 87 \mathrm{~N}(4)$ & S80I (4) \\
\hline & 2 & 16 & 512 & 16 & 16 & S83L (6) & D87N (4) & S80I (6) \\
\hline & 4 & 16 & 512 & 16 & 32 & S83L (10) & D87N (10) & S80I (10) \\
\hline & 6 & 32 & $>1024$ & 32 & 32 & S83L (10) & D87N (10) & S80I (10) \\
\hline & 11 & 32 & $>1024$ & 32 & 32 & S83L (10) & D87N (4) & S80I (6) \\
\hline & 16 & 128 & $>1024$ & 32 & 32 & S83L (10) & D87N (4) D87Y (6) & S80I (10) \\
\hline & 21 & 128 & $>1024$ & 32 & 32 & S83L (10) & D87N (10) & S80I (10) \\
\hline & 26 & 128 & $>1024$ & 32 & 32 & S83L (10) & D87N (10) & S80I (10) \\
\hline \multirow{7}{*}{$\begin{array}{l}\text { After CIP } \\
\text { withdrawal }\end{array}$} & 31 & 128 & $>1024$ & 32 & 32 & S83L (10) & D87N (10) & S80I (10) \\
\hline & 36 & 32 & $>1024$ & 32 & 32 & S83L (10) & D87N (2) D87Y (8) & S80I (10) \\
\hline & 41 & 64 & $>1024$ & 16 & 16 & S83L (10) & D87N (10) & S80I (10) \\
\hline & 46 & 32 & 512 & 16 & 32 & S83L (10) & D87N (10) & S80I (10) \\
\hline & 51 & 8 & 512 & 16 & 16 & S83L (10) & D87N (4) & S80I (4) \\
\hline & 56 & 0.5 & 64 & 2 & 2 & S83L (10) & $\ldots$ & $\ldots$ \\
\hline & 61 & 1 & 64 & 2 & 2 & S83L (10) & $\ldots$ & $\ldots$ \\
\hline
\end{tabular}

CIP: Ciprofloxacin, NAL: Nalidixic acid, NOR: Norfloxacin, LVX: Levofloxacin, MIC: Minimal inhibitory concentration, n: number of E. coli with a point mutation.

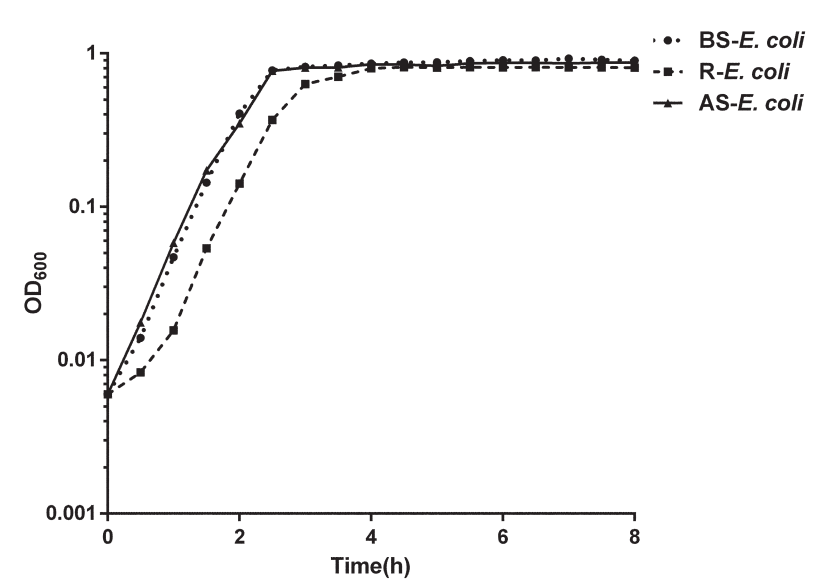

Fig. 3. Growth profiles of E. coli clones (n=5) from before ciprofloxacin administration (BS-E. coli, QSEC), after ciprofloxacin administration (R-E. coli, QREC) and after ciprofloxacin administration (AS-E. coli, QSEC).

\section{than QSEC clones (Fig. 3).}

\section{DISCUSSION}

This study was specifically designed to analyze the timeeffect relationship between ciprofloxacin administration and quinolones resistance in fecal E. coli of finishing pigs and to test the hypothesis that the emergence of resistance in pigs requires drug accumulation for 7 days or more. A certain amount of QREC isolates was present in the intestine of pigs before ciprofloxacin administration, suggesting that resistant isolates could colonize the swine intestine, which is consistent with previous research [27]. The use of antimicrobials can influence the number of intestinal microbiota in swine immediately [22], but the influence becomes smaller as time goes on, as the swine intestinal ecosystem was previously shown to remain stable with or without antimicrobial pressure [30]. The dynamic changes in the number of QREC and total $E$. coli isolates suggest this. We found that a low-level dose $(5 \mathrm{mg} / \mathrm{kg})$ of ciprofloxacin alone could alter the number of QREC isolates, but not the total number of $E$. coli isolates from feces of pigs. A recent study also showed that chlortetracycline alone at a low-level dose $(50 \mathrm{~g} / \mathrm{ton})$ had little effect on the microbial population of swine feces [24]. But, in another study that investigated the intestinal microbiota after feeding a performance-enhancing mixture of 3 antimicrobials (chlortetracycline $100 \mathrm{~g} /$ ton, sulfamethazine $100 \mathrm{~g} /$ ton and penicillin $50 \mathrm{~g} /$ ton) to pigs, an increase was found in the E. coli population [20].

The correlation between emergence of ciprofloxacin-resistant bacteria and ciprofloxacin treatment in humans or swine has been well characterized in recent years [11, 22]. However, how medication time influences the emergence of resistance has not been revealed. According to the dynamics of the MIC, we found that just 3 days were needed to develop quinolone resistance to fecal E. coli of pigs, which proves that our hypothesis that the emergence of resistance in pigs requires drug accumulation for 7 days or more is invalid. Removing antimicrobial pressure can reduce the number of resistant bacteria, but the seeds of resistance could colonize in the animal farm environment for a long time [31]. The dynamics of the MIC after ciprofloxacin withdrawal suggest this view.

In China, quinolones have been used as therapy or feed additives in animals for many years, which has resulted in high quinolone resistance in bacteria $[6,18,33]$. The mechanism of quinolone resistance is mainly mediated by the mutation of gyrA and parC genes [15]. In this study, when the max 
MIC of QSEC to CIP was $1 \mu \mathrm{g} / \mathrm{m} l$ or less, only the $g y r A$ mutation was detected; but, when the max MIC was $16 \mu \mathrm{g} / \mathrm{m} l$ or more, mutations of gyrA and parC were both detected. These results suggest that mutations of the gyr $A$ gene could not mediate high-level quinolone resistance, but are necessary for high-level resistance, which is in agreement with previous reports [25, 29]. Low-level quinolone resistance can also be mediated by PMQR genes [28]. However, we detected none of the described PMQR genes, suggesting that the emergency of QREC has little relation to the PMQR genes in this study.

There was no similarity between $E$. coli clones that were separated from feces before ciprofloxacin administration, during ciprofloxacin administration and after ciprofloxacin withdrawal, illustrating that de novo selection of resistance mutants from the initial microbiota was not the cause of emergence of QREC. Moreover, no plasmid-mediated resistance genes were detected in QSEC and QREC clones. Thus, the emergence of QREC may be caused by 2 possibilities: (1) enrichment of QREC in the initial gut microbiota and (2) exogenously acquired resistant bacteria. In both the EP and CP groups, we found a certain number of QREC isolates $\left(10^{8}\right.$ CFU) in feces from pigs before ciprofloxacin administration. Therefore, we are inclined to believe that the more likely cause of QREC emergence was the enrichment of QREC in the initial gut microbiota.

It has been reported that some mutations can influence bacterial fitness [21]. In this study, we found that the QREC had a selective advantage from day 31 to day 56, suggesting that the antimicrobial pressure did not disappear immediately after ciprofloxacin withdrawal, which is in agreement with a previous report [22]. QREC with mutations in gyrA and $\operatorname{parC}$ may have a fitness cost without antimicrobial pressure $[1,26]$. However, our findings indicate that without antimicrobial pressure, QREC lost its selective advantage after 26 days of ciprofloxacin treatment.

The potential limitations of our study should be addressed. First, fecal samples were picked from just 5 different locations in the pens, but there were 13 pigs in each pen. This may have led to potential bias in some results of our study. Second, QREC isolates, which were present in feces at a low concentration before ciprofloxacin administration, may have been missed when we selected only 10 clones for further research. Finally, we did not determine the concentration of ciprofloxacin in feces. This may have led to a lack of information about the relationship between $E$. coli resistance and antimicrobial residues.

The emergence of QREC in fecal microbiota is a complex phenomenon. It has been shown that exogenous acquisition of resistant isolates is the cause for the emergence of QREC from an individual's feces [8]. However, our results suggest that the enrichment of QREC in the initial gut microbiota is the more probable cause for the emergence of fecal QREC after feeding ciprofloxacin to pigs.

ACKNOWLEDGMENTS. This work was supported by National Basic Research Program of China (2013CB127200) and Natural Science Foundation of China (31070108). We would like to thank Yi-jiang Chen and Zi-kun Dong from
XinYiZhou pig farm for help in preparing and raising pigs.

\section{REFERENCES}

1. Abdelraouf, K., Kabbara, S., Ledesma, K. R., Poole, K. and Tam, V. H. 2011. Effect of multidrug resistance-conferring mutations on the fitness and virulence of Pseudomonas aeruginosa. $J$. Antimicrob. Chemother. 66: 1311-1317. [Medline] [CrossRef]

2. Andremont, A. 2003. Commensal flora may play key role in spreading antibiotic resistance. ASM News 69: 601-607.

3. Bertschinger, H.U. and Gyles, C.L. 1994. Oedema disease of pigs. pp. 193-219. In: Escherichia coli in Domestic Animals and Humans (Gyles, C.L. ed.), CAB International, Wallingford.

4. Clinical and Laboratory Standards Institute. 2008. Performance standards for antimicrobial susceptibility testing. 15th Informational Supplement. CLSI document M100-S18. Clinical and Laboratory Standards Institute, Wayne.

5. Costa, D., Poeta, P., Sáenz, Y., Coelho, A.C., Matos, M., Vinué, L., Rodrigues, J. and Torres, C. 2008. Prevalence of antimicrobial resistance and resistance genes in faecal Escherichia coli isolates recovered from healthy pets. Vet. Microbiol. 127: 97-105. [Medline] [CrossRef]

6. Dai, L., Lu, L.M., Wu, C.M., Li, B.B., Huang, S.Y., Wang, S.C., Qi, Y.H. and Shen, J.Z. 2008. Characterization of antimicrobial resistance among Escherichia coli isolates from chickens in China between 2001 and 2006. FEMS Microbiol. Lett. 286: 178-183. [Medline] [CrossRef]

7. Dalla-Costa, L. M., Irino, K., Rodrigues, J., Rivera, I. N. and Trabulsi, L. R. 1998. Characterisation of diarrhoeagenic Escherichia coli clones by ribotyping and ERIC-PCR. J. Med. Microbiol. 47: 227-234. [Medline] [CrossRef]

8. de Lastours, V., Cambau, E., Guillard, T., Marcade, G., Chau, F. and Fantin, B. 2012. Diversity of individual dynamic patterns of emergence of resistance to quinolones in Escherichia coli from the fecal flora of healthy volunteers exposed to ciprofloxacin. $J$. Infect. Dis. 206: 1399-1406. [Medline] [CrossRef]

9. Drago, L., Nicola, L., Mattina, R. and De Vecchi, E. 2010. In vitro selection of resistance in Escherichia coli and Klebsiella spp. at in vivo fluoroquinolone concentrations. BMC Microbiol. 10: 119. [Medline] [CrossRef]

10. Fairbrother, J. M., Nadeau, É. and Gyles, C. L. 2005. Escherichia coli in postweaning diarrhea in pigs: an update on bacterial types, pathogenesis, and prevention strategies. Anim. Health Res. Rev. 6: 17-39. [Medline] [CrossRef]

11. Fantin, B., Duval, X., Massias, L., Alavoine, L., Chau, F., Retout, S., Andremont, A. and Mentré, F. 2009. Ciprofloxacin dosage and emergence of resistance in human commensal bacteria. J. Infect. Dis. 200: 390-398. [Medline] [CrossRef]

12. Giraud, E., Cloeckaert, A., Baucheron, S., Mouline, C. and Chaslus-Dancla, E. 2003. Fitness cost of fluoroquinolone resistance in Salmonella enterica serovar Typhimurium. J. Med. Microbiol. 52: 697-703. [Medline] [CrossRef]

13. Heisig, P. 1996. Genetic evidence for a role of parC mutations in development of high-level fluoroquinolone resistance in Escherichia coli. Antimicrob. Agents Chemother. 40: 879-885. [Medline]

14. Heisig, P. and Tschorny, R. 1994. Characterization of fluoroquinolone-resistant mutants of Escherichia coli selected in vitro. Antimicrob. Agents Chemother. 38: 1284-1291. [Medline] [CrossRef]

15. Hooper, D. C. 1999. Mechanisms of fluoroquinolone resistance. Drug Resist. Updat. 2: 38-55. [Medline] [CrossRef]

16. Imberechts, H., Greve, H. D. and Lintermans, P. 1992. The 
pathogenesis of edema disease in pigs. Vet. Microbiol. 31: 221-233. [Medline] [CrossRef]

17. Lei, T., Tian, W., He, L., Huang, X.H., Sun, Y.X., Deng, Y.T., Sun, Y., Lv, D.H., Wu, C.M., Huang, L.Z., Shen, J.Z. and Liu, J.H. 2010. Antimicrobial resistance in Escherichia coli isolates from food animals, animal food products and companion animals in China. Vet. Microbiol. 146: 85-89. [Medline] [CrossRef]

18. Liu, J.H., Wei, S.Y., Ma, J.Y., Zeng, Z.L., Lü, D.H., Yang, G.X. and Chen, Z.L. 2007. Detection and characterisation of CTX$M$ and $C M Y-2$ beta-lactamases among Escherichia coli isolates from farm animals in Guangdong Province of China. Int. J. Antimicrob. Agents 29: 576-581. [Medline] [CrossRef]

19. Looft, T., Johnson, T. A., Allen, H. K., Bayles, D. O., Alt, D. P., Stedtfeld, R. D., Sul, W. J., Stedtfeld, T. M., Chai, B., Cole, J. R., Hashsham, S. A., Tiedje, J. M. and Stanton, T. B. 2012. In-feed antibiotic effects on the swine intestinal microbiome. Proc. Natl. Acad. Sci. U.S.A. 109: 1691-1696. [Medline] [CrossRef]

20. Marchant, M. and Moreno, M. A. 2013. Dynamics and diversity of Escherichia coli in animals and system management of the manure on a commercial farrow-to-finish pig farm. Appl. Environ. Microbiol. 79: 853-859. [Medline] [CrossRef]

21. Marcusson, L. L., Frimodt-Møller, N. and Diarmaid, H. 2009. Interplay in the selection of fluoroquinoloneresistance and bacterial fitness. PLoS Pathog. 5: e1000541. [Medline] [CrossRef]

22. Nguyen, T. T., Chachaty, E., Huy, C., Cambier, C., de Gunzburg, J., Mentré, F. and Andremont, A. 2012. Correlation between fecal concentrations of ciprofloxacin and fecal counts of resistant enterobacteriaceae in piglets treated with ciprofloxacin: toward new means to control the spread of resistance? Antimicrob. Agents Chemother. 56: 4973-4975. [Medline] [CrossRef]

23. Oram, M. and Fisher, L. M. 1991. 4-Quinolone resistance mutations in the DNA gyrase of Escherichia coli clinical isolates identified by using the polymerase chain reaction. Antimicrob. Agents Chemother. 35: 387-389. [Medline] [CrossRef]

24. Poole, T. L., Suchodolski, J. S., Callaway, T. R., Farrow, R. L., Loneragan, G. H. and Nisbet, D. J. 2013. The effect of chlortetracycline on faecal microbial populations in growing swine. $J$.
Glob. Antimicrob. Resist. 1: 171-174. [CrossRef]

25. Ruiz, J. 2003. Mechanisms of resistance to quinolones: target alterations, decreased accumulation and DNA gyrase protection. $J$. Antimicrob. Chemother. 51: 1109-1117. [Medline] [CrossRef]

26. Sander, P., Springer, B., Prammananan, T., Sturmfels, A., Kappler, M., Pletschette, M. and Böttger, E. C. 2002. Fitness cost of chromosomal drug resistance-conferring mutations. Antimicrob. Agents Chemother. 46: 1204-1211. [Medline] [CrossRef]

27. Schierack, P., Kadlec, K., Guenther, S., Filter, M., Schwarz, S., Ewers, C. and Wieler, L. H. 2009. Antimicrobial resistances do not affect colonization parameters of intestinal E. coli in a small piglet group. Gut Pathog. 1: 18. [Medline] [CrossRef]

28. Strahilevitz, J., Jacoby, G. A., Hooper, D. C. and Robicsek, A. 2009. Plasmid-mediated quinolone resistance: a multifaceted threat. Clin. Microbiol. Rev. 22: 664-689. [Medline] [CrossRef]

29. Tavío, M. M., Vila, J., Ruiz, J., Ruiz, J., Matín-Sánchez, A. M. and Jiménez de Anta, M. T. 1999. Mechanisms involved in the development of resistance to fluoroquinolones in Escherichia coli isolates. J. Antimicrob. Chemother. 44: 735-742. [Medline] [CrossRef]

30. Vollaard, E. J. and Clasener, H. A. 1994. Colonization resistance. Antimicrob. Agents Chemother. 38: 409-414. [Medline] [CrossRef]

31. Wegener, H. C. 2003. Antibiotics in animal feed and their role in resistance development. Curr. Opin. Microbiol. 6: 439-445. [Medline] [CrossRef]

32. Witte, W. 2000. Selective pressure by antibiotic use in livestock. Int. J. Antimicrob. Agents 16: 19-24. [Medline] [CrossRef]

33. Yang, H., Chen, S., White, D. G., Zhao, S., McDermott, P., Walker, R. and Meng, J. 2004. Characterization of multipleantimicrobial-resistant Escherichia coli isolates from diseased chickens and swine in China. J. Clin. Microbiol. 42: 3483-3489. [Medline] [CrossRef]

34. Zhang, L., Huang, Y., Zhou, Y., Buckley, T. and Wang, H. H. 2013. Antibiotic administration routes significantly influence the levels of antibiotic resistance in gut microbiota. Antimicrob. Agents Chemother. 57: 3659-3666. [Medline] [CrossRef] 